\title{
openheart Mortality pattern and cause of death in a long-term follow-up of patients with STEMI treated with primary PCI
}

\author{
Ataollah Doost Hosseiny, ${ }^{1}$ Soniah Moloi, ${ }^{1}$ Jaya Chandrasekhar, ${ }^{2}$ Ahmad Farshid ${ }^{1,3}$
}

To cite: Doost Hosseiny A, Moloi S, Chandrasekhar J, et al. Mortality pattern and cause of death in a long-term follow-up of patients with STEMI treated with primary PCI. Open Heart 2016;3: e000405. doi:10.1136/ openhrt-2016-000405

Received 12 January 2016 Accepted 15 March 2016

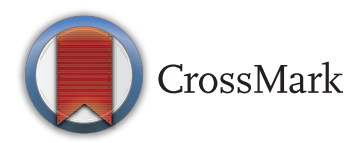

${ }^{1}$ Cardiology Department, The Canberra Hospital, Garran, Australian Capital Territory, Australia

${ }^{2}$ Icahn School of Medicine at Mount Sinai, Greater New York City Area, New York, USA

${ }^{3}$ Australian National University, Canberra Australian Capital Territory, Australia

\section{Correspondence to} Dr Ataollah Doost Hosseiny; ata.doosthosseiny@act.gov. au

\section{ABSTRACT}

Objective: We aimed to assess the pattern of mortality and cause of death in a cohort of patients with ST-segment elevation myocardial infarction (STEMI) treated with primary percutaneous coronary intervention (PCI).

Methods: Consecutive patients with STEMI treated with primary PCI during 2006-2013 were evaluated with a mean follow-up of 3.5 years (1-8.4 years). We used hospital and general practice records and mortality data from The Australian National Death Index.

Results: Among 1313 patients (22.5\% female) with mean age of $62.3 \pm 13.1$ years, 181 patients $(13.7 \%)$ died during long-term follow-up. In the first 7 days, 45 patients $(3.4 \%)$ died, $76 \%$ of these due to cardiogenic shock. Between 7 days and 1 year, another 50 patients died (3.9\%), 58\% from cardiovascular causes and $22 \%$ from cancer. Beyond 1 year, there were 86 deaths with an estimated mean mortality rate of $2.05 \%$ per year, $36 \%$ of deaths were cardiovascular and $52 \%$ non-cardiovascular, including 29\% cancer-related deaths. On multivariate analysis, age $\geq 75$ years, history of diabetes, prior $\mathrm{PCl}$, cardiogenic shock, estimated glomerular filtration rate (eGFR) $<60$ and symptom-toballoon time $>360$ min were independent predictors of long-term mortality. In 16 patients who died of sudden cardiac death postdischarge, only $4(25 \%)$ had ejection fraction $\leq 35 \%$ and would have been eligible for an implantable cardioverter defibrillator.

Conclusions: In the era of routine primary $\mathrm{PCI}$, we found a mortality rate of $7.3 \%$ at 1 year, and $2.05 \%$ per year thereafter. Cause of death was predominantly cardiovascular in the first year and mainly noncardiovascular after 1 year. Age, diabetes, prior PCI, cardiogenic shock, eGFR $<60$ and delayed treatment were independent predictors of mortality.

\section{BACKGROUND}

Primary percutaneous coronary intervention (PCI) is the treatment of choice for patients with ST-segment elevation myocardial infarction (STEMI), when performed by experienced operators in a timely fashion, as demonstrated in randomised trials and recommended by international guidelines. ${ }^{1} 2$ However, primary PCI trials have generally

\section{KEY QUESTIONS}

What is already known about this subject?

- Mortality rates have decreased after ST-segment elevation myocardial infarction (STEMI) in the last decade, in line with increased use of primary percutaneous coronary intervention $(\mathrm{PCl})$ and evidencebased medications.

What does this study add?

- Mortality rate was $4.3 \%$ at 30 days and $7.3 \%$ at 1 year in a contemporary cohort of patients with STEMI treated with primary $\mathrm{PCl}$. Majority of deaths were cardiovascular before 1 year and non-cardiovascular after 1 year.

How might this impact on clinical practice?

- Knowing that the majority of deaths in the first year are cardiovascular can inform the development of effective preventative strategies to further improve outcomes after STEMI.

recruited selected patients and may have excluded those with high-risk features such as advanced age, cardiogenic shock, high bleeding risk, recent cerebrovascular event or ventilated patients. There is little contemporary data on long-term prognosis and cause of death in consecutive real-world patients with STEMI.

There is evidence to suggest that mortality rates for patients with STEMI have declined in recent years. ${ }^{3}{ }^{4}$ This may be related to advances in pharmacotherapy, greater accessibility of primary PCI and development of international clinical guidelines for management of STEMI. Nevertheless, STEMI remains a common and challenging clinical condition with a high risk of mortality. Each year, there are about 258000 STEMI presentations to emergency department (ED) in the USA, with incidence rate of 7.3 per $10000 .^{5}$

Our aim was to study the timing and causes of death in a contemporary cohort of consecutive patients with STEMI treated with primary PCI. This information would be important to develop new strategies and 
secondary prevention programmes to reduce early mortality and improve long-term prognosis in this group. ${ }^{67}$

\section{METHODS}

\section{Study setting}

We analysed the primary PCI registry at The Canberra Hospital, a tertiary referral centre in the Australian Capital Territory (ACT), offering a 24/7 primary PCI service. In addition to our ED, there are two referring EDs $15 \mathrm{~km}$ away with a travel time of 20-30 min. The catheterisation laboratory was activated by ED physicians for patients with STEMI within $12 \mathrm{~h}$ of symptoms who presented directly to the ED, or who had an ECG performed in the field by ambulance paramedics.

A system of catheterisation laboratory activation has been in place since 2000 for patients with STEMI who presented to EDs in our region. In 2009, regional ambulances were equipped with 12-lead ECG machines and transmission systems, and paramedics were trained and assessed in 12-lead ECG interpretation.

All patients with STEMI received aspirin $300 \mathrm{mg}$, plus either clopidogrel $600 \mathrm{mg}$ or prasugrel $60 \mathrm{mg}$ (if $<75$ years, $>60 \mathrm{~kg}$ in weight with no history of transient ischaemic attack/cerebrovascular events), and unfractionated heparin $5000 \mathrm{U}$ intravenously prior to arrival at the catheterisation laboratory. Pretreatment with prasugrel became available in 2011. PCI procedures were performed by six operators through femoral or radial access. Treatment with further doses of heparin, glycoprotein IIb/IIIa inhibitors and the use of intra-aortic balloon pump and aspiration devices were at the discretion of the operator.

The majority of patients included in this study had transthoracic echocardiography (TTE) performed either before or soon after discharge. Left ventricular ejection fraction (LVEF) was calculated using the quantitative two-dimensional (biplane Simpson's) method. Glomerular filtration rate (GFR) was estimated for all patients before the procedure using the CKD-EPI formula. ${ }^{8}$

Demographics and procedural data for consecutive patients with STEMI treated with primary PCI were prospectively entered into the registry. The study was approved by the ACT Health Research Ethics Committee, and consent for data collection and follow-up was obtained for all patients. There were no exclusion criteria. Patients who died after the start of the procedure were entered into the registry and included in the analysis, but patients who died before the start of the procedure were not included. Follow-up data were routinely collected in hospital and at 12 months by letter, phone call, clinic review or review of files.

\section{Data linkage with National Death Index}

In order to confirm the cause and time of death, we also obtained approval to access the Australian Institute of Health and Welfare National Death Index. The
National Death Index utilises the 10th version of the International Statistical Classification of Disease and Related Health Problems to standardise the cause of death. The patient's name, date of birth and residential address were matched with data on the National Death Index. We accepted a match when a patient on the National Death Index had the same name and date of birth as a patient in our registry.

\section{Definitions and end points}

STEMI was diagnosed if a patient had ischaemic symptoms associated with ST-segment elevation of $\geq 0.2 \mathrm{mV}$ in at least two contiguous precordial or $\geq 0.1 \mathrm{mV}$ in two adjacent limb leads, left bundle branch block, or extensive ST-segment depression in the precordial leads representing posterior myocardial infarction (MI).

The primary end point was incidence of all-cause death. The secondary end point was cause of death. Cardiogenic shock was defined as blood pressure $<90 \mathrm{~mm} \mathrm{Hg}$ or requirement for inotropic therapy due to cardiac dysfunction. Sudden death was defined as death that followed abrupt loss of consciousness with or without preceding cardiac symptoms. Unwitnessed death in the setting of treatment for a major illness such as malignancy or infection was assumed to be caused by the illness. Cardiovascular death was defined as death due to reinfarction, cardiogenic shock, cardiac failure, sudden death or stroke. Stent thrombosis was defined as definite stent thrombosis by angiography, and reinfarction was defined according to the third universal definition of MI. ${ }^{9}$ Stroke was defined as a new focal neurological deficit lasting more than $24 \mathrm{~h}$ and confirmed by imaging.

Symptom onset time was the time recalled by the patient as the onset of symptoms. Symptom-to-balloon (STB) time was defined as the time from self-reported onset of symptoms to time of first device delivery in the culprit artery.

\section{Statistical analysis}

Categorical data are presented as frequencies and percentages and analysed with $\chi^{2}$ tests or Fisher's exact test. Continuous variables are presented as mean and SD or median and IQR and were analysed using Student's t test or Wilcoxon rank-sum test. Patient survival was analysed with Kaplan-Meier curves. Multivariate Cox proportional hazards analysis was used to assess the relationship of baseline variables, treatment delay and other factors with mortality during follow-up. Factors entered into the model included age $\geq 75$ years, sex, cardiac risk factors, presentation with out-of-hospital cardiac arrest, cardiogenic shock, estimated GFR (eGFR) $<60$, use of prasugrel and glycoprotein IIb/IIIa inhibitors, STB time of $>360 \mathrm{~min}$ and Thrombolysis In Myocardial Infarction (TIMI) flow score. A forward likelihood ratio method was used to enter factors into the regression model. All analyses were two-tailed and a $\mathrm{p}$ value of $<0.05$ was 
considered statistically significant. Analyses were performed using SPSS V.22 software (IBM, New York, USA).

\section{RESULTS}

We treated 1313 consecutive patients with STEMI with primary PCI between January 2006 and December 2013. Mean age was $62.3 \pm 13.1$ years, and $1017(77.5 \%)$ were male. Mean length of follow-up was $1276 \pm 855$ days (3.5 years), and median follow-up was 1159 days (IQR 578-1917 days). During this period, 181 patients died. Table 1 shows the baseline characteristics for the cohort, patients who survived during follow-up and those who died. Patients who died were on average 11.5 years older with a greater proportion of women (30.6\% compared with $21.3 \%$ of those who survived, $\mathrm{p}=0.0073$ ). Those who died were also more likely to have a history of diabetes and prior PCI and less likely to be smokers or have a family history of premature ischaemic heart disease.

Procedural variables are shown in table 2. On univariate analysis, longer ischaemic times, reduced eGFR, lack of procedural success, cardiogenic shock, cardiac arrest and final TIMI flow score $<3$ were significantly associated with increased risk of mortality. There was a higher rate of multivessel PCI in the group who died during follow-up (71 $(6.3 \%)$ in survivors vs $19(10.9 \%)$ in those who died, $\mathrm{p}=0.038$ ), although overall numbers were small.

Kaplan-Meier survival analysis was used to estimate allcause and cardiovascular mortality rates for patients at various time points (figure 1 and table 3 ). There were 45 deaths in the first 7 days following primary PCI at an estimated mortality rate of $3.4 \%$. Between 7 days and 1 year, there were 50 deaths and an estimated mortality rate of $3.9 \%$. There were 86 deaths after 1 year with an estimated mean mortality rate of $2.05 \%$ per year between 1 and 5 years. On Cox proportional hazards multivariate analysis, we found that age $\geq 75$ years, history of diabetes or prior PCI, cardiogenic shock, eGFR $<60$ and STB time $>360 \mathrm{~min}$ to be independent predictors of mortality during long-term follow-up (table 4).

Cause of death was distinctly different in patients in these time intervals (tables 5 and 6 and figure 2). During the first week, cardiovascular causes were responsible for $98 \%$ of deaths ( $76 \%$ of these due to cardiogenic shock). Between 7 days and 1 year, cardiovascular causes accounted for $58 \%$ and malignancy for $22 \%$ of all deaths. After 1 year, $36 \%$ of deaths were cardiovascular and $52 \%$ noncardiovascular, including cancer which accounted for $29 \%$ of all deaths. Cause of death was undetermined in 14 patients $(8 \%)$.

Echocardiography was available on 139 of 181 patients who died $(76 \%)$ and an LVEF $\leq 35 \%$ was found in 39 patients $(21.5 \%)$. Among 16 patients who died of sudden cardiac death (SCD) postdischarge, 4 patients (25\%) had $\mathrm{LVEF} \leq 35 \%$ and would have been eligible for an implantable cardioverter defibrillator (ICD). In eight patients, LVEF was greater than $35 \%$, and in four patients, TTE was not available. The incidence of SCD was $0.8 \%$ of the total cohort at 1 year and $1.1 \%$ at 3 years.

\section{DISCUSSION}

Our study has demonstrated three distinct phases with regard to mortality risk after primary PCI for treatment of STEMI. In the first 7 days, there was a relatively high risk of death $(3.4 \%)$, mainly due to cardiogenic shock and associated multiorgan failure. Between 7 days and 1 year, $3.9 \%$ of all patients died, indicating a significantly lower mortality rate. During this period, cardiovascular causes constituted the majority of deaths. Beyond 1 year, mortality rate was stable at $2.05 \%$ per year, with noncardiovascular causes of death outnumbering cardiovascular causes and cancer accounting for $29 \%$ of all deaths.

Table 1 Baseline characteristics of patients with STEMI treated with primary PCI who died or survived during a mean follow-up of 3.5 years

\begin{tabular}{lllll}
\hline & Total cohort $\mathbf{n = 1 3 1 3}$ & Survived during follow-up $\mathbf{n = 1 1 3 2}$ & Died during follow-up $\mathbf{n = 1 8 1}$ & $\mathbf{p}$ Value \\
\hline Mean age & $62.3 \pm 13.1$ & $60.8 \pm 12.2$ & $72.3 \pm 13.0$ & \\
Females & $296(22.5 \%)$ & $241(21.3 \%)$ & $55(30.4 \%)$ & $126(69.6 \%)$ \\
Males & $1017(77.5 \%)$ & $891(78.7 \%)$ & $27.4 \pm 6.0$ & 0.0073 \\
BMI $^{*}$ & 28.0 & $28.0 \pm 4.9$ & $42(23.3 \%)$ & 0.314 \\
Diabetes & $214(16.3 \%)$ & $172(15.2 \%)$ & $88(48.9 \%)$ & 0.0084 \\
Hypertension & $564(43.0 \%)$ & $476(42.1 \%)$ & $33(18.3 \%)$ & 0.086 \\
Smoker & $375(28.6 \%)$ & $342(30.2 \%)$ & $29(16.1 \%)$ & 0.0007 \\
Ex-smoker & $258(19.7 \%)$ & $229(20.2 \%)$ & $47(26.1 \%)$ & 0.187 \\
Hyperlipidaemia & $399(30.4 \%)$ & $352(31.1 \%)$ & $30(16.7 \%)$ & 0.172 \\
Family history & $373(28.4 \%)$ & $343(30.3 \%)$ & $28(16.6 \%)$ & \\
Prior PCl† & $121(9.6 \%)$ & $93(8.5 \%)$ & $9(5.3 \%)$ & 0.0001 \\
Prior CABG & $43(3.4 \%)$ & $34(3.1 \%)$ & & 0.169 \\
\hline
\end{tabular}

${ }^{*}$ Body mass index.

†Percutaneous coronary intervention.

¥Coronary artery bypass grafting.

STEMI, ST-segment elevation myocardial infarction. 
Table 2 Procedural variables for patients with STEMI treated with primary PCI who died or survived during a mean follow-up of 3.5 years

\begin{tabular}{|c|c|c|c|c|}
\hline & $\begin{array}{l}\text { Total cohort } \\
\mathrm{N}=1313\end{array}$ & $\begin{array}{l}\text { Survived during follow-up } \\
n=1132\end{array}$ & $\begin{array}{l}\text { Died during follow-up } \\
n=181\end{array}$ & p Value \\
\hline Radial access & $111(8.5 \%)$ & 107 (9.5\%) & $4(2.2 \%)$ & 0.0002 \\
\hline Mean contrast volume & 146.3 & $146.1 \pm 51.6$ & $148.0 \pm 49.9$ & 0.669 \\
\hline STB $^{\star}$ time (minutes) & $198(140-345)$ & 195 (139-330) & $236(150-456)$ & 0.01 \\
\hline STB time $>360 \mathrm{~min}$ & $239(23.8 \%)$ & $190(22.1 \%)$ & $49(34.3 \%)$ & 0.0022 \\
\hline Prasugrel used & $243(18.7 \%)$ & $227(20.1 \%)$ & $16(9.2 \%)$ & 0.0002 \\
\hline $\begin{array}{l}\text { Glycoprotein IIb-IIla } \\
\text { used }\end{array}$ & $597(50.9 \%)$ & $516(50.6 \%)$ & $81(52.3 \%)$ & 0.71 \\
\hline Estimated GFR† & 74.1 & $76.8 \pm 15.8$ & $56.7 \pm 22.6$ & $<0.0001$ \\
\hline Estimated GFR $<60$ & $256(19.6 \%)$ & $157(13.9 \%)$ & $99(55.9 \%)$ & $<0.0001$ \\
\hline Procedural success & $1272(98.2 \%)$ & $1108(98.8 \%)$ & $164(94.8 \%)$ & 0.0018 \\
\hline Cardiogenic shock & $92(7.0 \%)$ & $38(3.4 \%)$ & $54(29.8 \%)$ & $<0.0001$ \\
\hline Cardiac arrest & 25 (1.9\%) & $15(1.3 \%)$ & $10(5.7 \%)$ & 0.0009 \\
\hline 3-vessel disease & $242(18.8 \%)$ & $191(17.2 \%)$ & $51(29.3 \%)$ & 0.0003 \\
\hline \multicolumn{5}{|l|}{ Culprit artery } \\
\hline Left main & $4(0.3 \%)$ & $1(0.1 \%)$ & $3(1.7 \%)$ & 0.0088 \\
\hline LAD‡ & $559(42.7 \%)$ & $474(41.9 \%)$ & $85(48.0 \%)$ & 0.125 \\
\hline RCA§ & $525(40.1 \%)$ & $470(41.5 \%)$ & $55(31.1 \%)$ & 0.0075 \\
\hline LCxף & $204(15.6 \%)$ & $175(15.5 \%)$ & 29 (16.4\%) & 0.75 \\
\hline Graft & $17(1.3 \%)$ & $12(1.1 \%)$ & $5(2.8 \%)$ & 0.0676 \\
\hline$>1$ vessel treated & $90(7.0 \%)$ & $71(6.3 \%)$ & $19(10.9 \%)$ & 0.038 \\
\hline Initial TIMI** flow 0-1 & $742(57.7 \%)$ & $632(56.9 \%)$ & $110(63.2 \%)$ & 0.114 \\
\hline Final TIMI flow <3 & $99(7.7 \%)$ & $72(6.5 \%)$ & $27(15.7 \%)$ & 0.0001 \\
\hline >1 stent implanted & $328(26.7 \%)$ & $284(26.5 \%)$ & $44(27.9 \%)$ & 0.73 \\
\hline Drug-eluting stent & $295(23.0 \%)$ & $274(24.7 \%)$ & 21 (12.0\%) & 0.0001 \\
\hline Mean stent diameter & 3.23 & $3.26 \pm 1.5$ & $3.06 \pm 0.42$ & 0.11 \\
\hline Stent length & 17.3 & $17.4 \pm 5.3$ & $17.1 \pm 5.2$ & 0.62 \\
\hline \multicolumn{5}{|c|}{$\begin{array}{l}\text { *Symptom-to-balloon time. } \\
\text { †Glomerular filtration rate. } \\
\text { fLeft anterior descending artery. } \\
\text { §Right coronary artery. } \\
\text { १Left circumflex artery. } \\
\text { **Thrombolysis In Myocardial Infarction flow score. } \\
\text { PCI, percutaneous coronary intervention; STEMI, ST-segment elevation myocardial infarction. }\end{array}$} \\
\hline
\end{tabular}

Mortality rate after STEMI has decreased over the past two decades in parallel with more widespread use of evidence-based treatments including primary PCI and

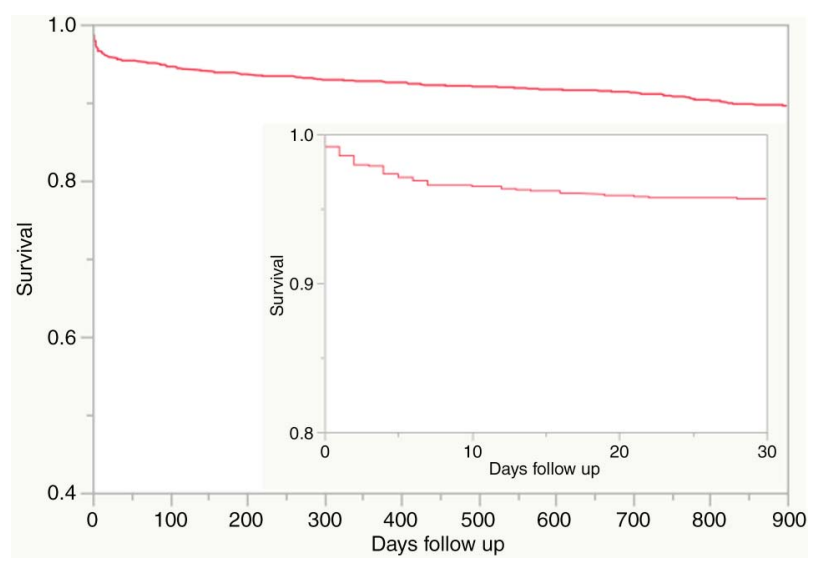

Figure 1 Kaplan-Meyer survival curve of 1313 patients following primary $\mathrm{PCl}$. The main figure shows survival to 900 days, and the smaller figure shows survival to 30 days. $\mathrm{PCl}$, percutaneous coronary intervention. pharmacotherapy. According to the SWEDEHEART/ RIKS-HIA registry, 1-year mortality decreased from $21 \%$ in 1996 to $13.3 \%$ in 2007. During this time, use of primary PCI for management of STEMI increased from $12 \%$ to $61 \%$ and reperfusion therapy from $66 \%$ to $79 \% .^{10}$ The use of aspirin, clopidogrel, $\beta$-blockers, statins, and ACE inhibitors all increased significantly. ${ }^{10}$

Table 3 Cumulative incidence of all cause and cardiovascular mortality rate during follow-up based on the Kaplan-Meyer survival analysis

\begin{tabular}{lcl}
\hline & $\begin{array}{l}\text { Total mortality } \\
\text { (SE) }\end{array}$ & $\begin{array}{l}\text { Cardiovascular } \\
\text { mortality (SE) }\end{array}$ \\
\hline 7 days & $3.4 \%(0.005)$ & $3.4 \%(0.005)$ \\
30 days & $4.3 \%(0.006)$ & $4.2 \%(0.006)$ \\
1 year & $7.3 \%(0.007)$ & $5.6 \%(0.006)$ \\
2 years & $8.9 \%(0.008)$ & $6.4 \%(0.007)$ \\
3 years & $11.5 \%(0.009)$ & $7.1 \%(0.007)$ \\
4 years & $13.1 \%(0.01)$ & $7.4 \%(0.008)$ \\
5 years & $15.5 \%(0.012)$ & $8.6 \%(0.009)$ \\
\hline
\end{tabular}


Table 4 Cox proportional hazard multivariate analysis of predictors of mortality after primary $\mathrm{PCl}$

\begin{tabular}{lllc}
\hline & Risk ratio & $\mathbf{9 5 \%}$ Cl & p Value \\
\hline Age $\geq 75$ years & 2.19 & 1.74 to 2.58 & $<0.0001$ \\
Female sex & 1.10 & 0.74 to 1.64 & 0.644 \\
eGFR ${ }^{*}<60$ & 1.53 & 1.25 to 1.87 & $<0.0001$ \\
Diabetes & 1.73 & 1.14 to 2.62 & 0.01 \\
STB $>360$ min & 1.32 & 1.09 to 1.59 & 0.004 \\
Cardiogenic shock & 4.0 & 3.18 to 5.03 & $<0.0001$ \\
Prior PCl & 1.43 & 1.14 to 1.79 & 0.002 \\
\hline
\end{tabular}

*Estimated glomerular filtration rate.

†Symptom-to-balloon time.

$\ddagger$ Percutaneous coronary intervention.

Although STEMI mortality has decreased recently, data from PCI randomised trials and acute MI (AMI) registries indicate that the risk of mortality is still significant, particularly in the early phase after STEMI. In the HEAT-PPCI $^{11}$ and HORIZONS-AMI ${ }^{12}$ trials, mortality rates were $4.7 \%$ at 28 days and $2.3 \%$ at 30 days, respectively. However, these trials excluded high-risk patients and likely underestimate the true mortality risk in the community. In-hospital mortality rates for STEMI in the OPERA $^{13}$ and the Zurich-Acute Coronary Syndrome (Z-ACS) ${ }^{14}$ registries were $4.6 \%$ and $5.7 \%$, respectively. In a recent cohort of patients with STEMI in Denmark, ${ }^{15}$ all-cause mortality was reported as $7.9 \%$ at 30 days postprimary PCI. Our 30-day mortality rate of $4.3 \%$ in consecutive patients appears to be comparable to that in contemporary randomised trials.

Table 5 Cause of death (number and percentage of all deaths) during specified time intervals after primary $\mathrm{PCl}$

\begin{tabular}{|c|c|c|c|c|}
\hline $\begin{array}{l}\text { Cause of } \\
\text { death }\end{array}$ & $\begin{array}{l}0-7 \\
\text { days } \\
n=45 \\
(\%) \\
\end{array}$ & $\begin{array}{l}7 \text { days to } \\
1 \text { year } \\
n=50(\%)\end{array}$ & $\begin{array}{l}\text { After } \\
1 \text { year } \\
n=87 \\
(\%)\end{array}$ & $\begin{array}{l}\text { Total } \\
\text { deaths } \\
n=181 \\
(\%)\end{array}$ \\
\hline $\begin{array}{l}\text { Cardiogenic } \\
\text { shock }\end{array}$ & $34(76)$ & $6(12)$ & $0(0)$ & $40(22)$ \\
\hline $\mathrm{AMI}^{*}$ & $8(18)$ & $5(10)$ & $10(12)$ & $23(13)$ \\
\hline CCF† & $0(0)$ & 8 (16) & $7(8)$ & 15 (8) \\
\hline SCD $\ddagger$ & $2(4)$ & $8(16)$ & $8(9)$ & $18(10)$ \\
\hline Stroke & $0(0)$ & $2(4)$ & $6(7)$ & $8(4)$ \\
\hline Cancer & $0(0)$ & 11 (22) & 25 (29) & $36(20)$ \\
\hline Infection & $1(2)$ & $1(2)$ & $8(9)$ & $10(6)$ \\
\hline $\begin{array}{l}\text { Kidney } \\
\text { disease }\end{array}$ & $0(0)$ & $3(6)$ & 2 (2) & $5(3)$ \\
\hline $\begin{array}{l}\text { Lung } \\
\text { disease }\end{array}$ & $0(0)$ & $2(4)$ & $5(6)$ & 7 (4) \\
\hline Other & $0(0)$ & $0(0)$ & $5(6)$ & $5(3)$ \\
\hline Unspecified & $0(0)$ & $4(8)$ & $10(12)$ & $14(8)$ \\
\hline
\end{tabular}

Table 6 Types of cancer in 36 patients who died of cancer during follow-up after primary PCI for STEMI

\begin{tabular}{lc}
\hline Type of cancer & Number (\%) \\
\hline Lung & $10(28)$ \\
Prostate & $4(11)$ \\
Colorectal & $3(8)$ \\
Pancreas/bile duct & $3(8)$ \\
Renal cell & $2(6)$ \\
Bladder & $2(6)$ \\
Lymphoma & $2(6)$ \\
Salivary gland & $2(6)$ \\
Disseminated, unknown primary & $2(6)$ \\
Breast, melanoma, larynx, & 1 each \\
myeloproliferative, oesophageal, squamous & \\
cell & \\
\hline PCI, percutaneous coronary intervention; STEMI, ST-segment \\
elevation myocardial infarction.
\end{tabular}

During long-term follow-up, the PRAMI trial ${ }^{16}$ reported an all-cause mortality rate of $6 \%$ at 23 months, whereas the OPERA registry ${ }^{13}$ reported an all-cause mortality of $9 \%$ at 1 year. In our cohort, cumulative mortality rate was $7.3 \%$ and $8.9 \%$ at 1 and 2 years, respectively. It appears that early and long-term mortality rates are lower in clinical trials compared with community-based AMI registries, which may be as a result of exclusion of high-risk patients in clinical trials as opposed to consecutive enrolment of patients in registries.

Cause of death was significantly different in specific phases after STEMI, suggesting that distinct strategies should be considered in order to improve prognosis based on the recovery phase of the patient. Cardiogenic shock was the primary cause of death in the acute phase after STEMI. In view of the disappointing results of clinical trials of intra-aortic balloon pump and left ventricular (LV) assist devices in reducing mortality, ${ }^{17}{ }^{18}$ it appears reasonable to focus more attention on strategies to prevent this complication, which may be best achieved by reducing total ischaemic time. We have shown STB

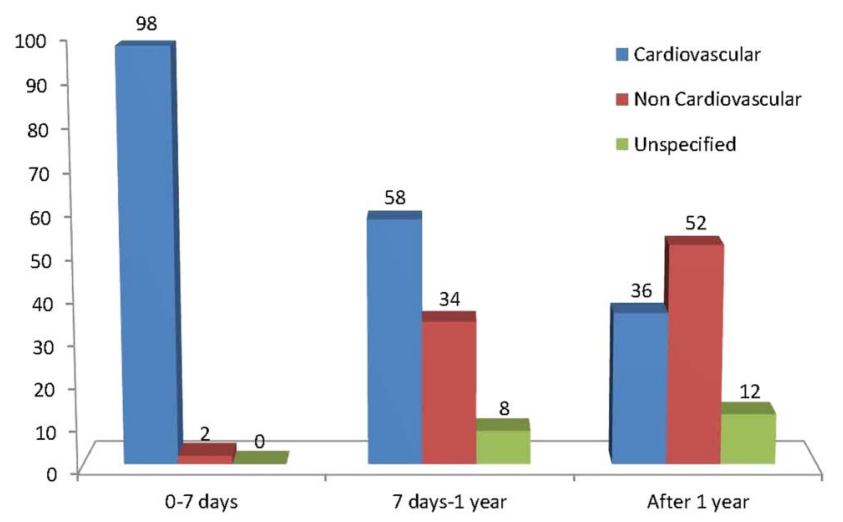

Figure 2 Percentage of mortality from cardiovascular or non-cardiovascular causes during specified phases after primary $\mathrm{PCl}$. $\mathrm{PCl}$, percutaneous coronary intervention. 
time $>360 \mathrm{~min}$ to be an independent predictor of mortality during long-term follow-up (table 4). Reducing STB time has been shown to be crucial in reducing the incidence of death post-STEMI. ${ }^{19}$ Over the past decade, door-to-balloon time for patients with STEMI has improved, but in-hospital mortality rate has remained virtually unchanged. ${ }^{20}$ We believe that in the current environment, reducing prehospital time offers the greatest opportunity to further improve prognosis after STEMI, and deserves more attention and allocation of resources. ${ }^{21}$

Treatment of non-culprit vessels in STEMI is an area of active research. At our institution, usual practice is to treat only the culprit artery acutely, unless there is uncertainty about the culprit artery, or the patient has cardiogenic shock with multiple severe lesions. More multivessel PCI was performed in the group of patients who died, but this was probably due to higher prevalence of cardiogenic shock. Therefore, no conclusions can be drawn from our results regarding benefits of multivessel PCI.

Between 7 days and 1 year, cardiovascular disease was the commonest cause of death, accounting for $58 \%$ of mortality. Antiplatelet therapy, $\beta$-blockers, reninangiotensin system inhibitors and statins have all been associated with improved short-term and long-term cardiovascular prognosis in patients with STEMI. ${ }^{22}$ Cardiac rehabilitation programmes have been shown to not only restore quality of life and improve functional capacity, but also reduce long-term mortality after AMI. ${ }^{6}{ }^{7}$ Our patients routinely received one session of education in hospital and were referred for a 6-week hospital-based cardiac rehabilitation programme. We believe close follow-up, focused attention on cardiac rehabilitation and the use of evidence-based medical management are the best strategies to reduce mortality further in this phase of recovery after STEMI.

We have identified diabetes and chronic kidney disease (CKD) to be independent risk factors for longterm mortality. In the PROSPECT trial, intravascular ultrasound imaging in patients with diabetes ${ }^{23}$ and $\mathrm{CKD}^{24}$ postacute coronary syndrome has shown longer lesions with a greater plaque burden and larger necrotic core and calcium content, compared with participants without these conditions. These patients should be specially targeted for aggressive and ongoing management of risk factors to reduce their higher mortality risk post-STEMI.

Beyond 1 year after STEMI, cardiovascular disease and malignancy were the most important causes of death. Continued periodic cardiology follow-up would appear to be appropriate to encourage healthy lifestyle choices and compliance with evidence-based treatments. Vigilance for occurrence of common cancers and participation in evidence-based cancer screening and management programmes should also be considered.

Another strategy for reducing late mortality in patients with STEMI is the use of ICD in those with severe LV systolic dysfunction beyond 40 days after a AMI. ${ }^{25}$ ICDs have been shown to improve prognosis post-MI with reducing the rate of SCD. ${ }^{26}$ In our cohort, only four patients who died with SCD after hospital discharge had LVEF $\leq 35 \%$ and would have been eligible for ICD insertion, potentially preventing $2 \%$ of all deaths in our cohort. Similar to the findings of a recent Japanese registry, ${ }^{27}$ we found a low incidence of SCD $(1.1 \%$ at 3 years) in STEMI survivors in the primary PCI era. Our results are in contrast to the ICD primary prevention trials $^{26}{ }^{28}$ which were performed in the 1990s when there was a much lower utilisation of contemporary evidence-based treatments such as primary PCI and pharmacotherapy. ${ }^{10}$

\section{Study limitations}

Despite extensive efforts and access to the Australian National Death Index, cause of death was not known for $8 \%$ of patients. Patients classified as having SCD may have died of non-cardiac causes such as ruptured aneurysm or pulmonary embolus.

\section{CONCLUSION}

In the era of routine primary PCI for STEMI, we found a mortality rate of $4.3 \%$ at 30 days and $7.3 \%$ at 1 year in consecutive patients. Cardiovascular conditions were the commonest cause of death until 1 year, after which cardiovascular disease and malignancy accounted for the majority of deaths. Prolonged STB time, eGFR $<60$ and diabetes were among the independent predictors of mortality. Our results inform discussions about opportunities to further improve survival after STEMI, which may include public education for early presentation, cardiac rehabilitation programmes and ongoing follow-up to encourage a healthy lifestyle and optimal medical management.

Acknowledgements The authors would like to acknowledge the contribution of Paul Marley in the Cardiology Research Unit, cardiologists and nurses of the cardiac catheter laboratory and CCU and cardiac technicians at the Canberra Hospital.

Competing interests None declared.

Ethics approval ACT Health Directorate Ethics Committee.

Provenance and peer review Not commissioned; externally peer reviewed.

Data sharing statement No additional data are available.

Open Access This is an Open Access article distributed in accordance with the Creative Commons Attribution Non Commercial (CC BY-NC 4.0) license, which permits others to distribute, remix, adapt, build upon this work noncommercially, and license their derivative works on different terms, provided the original work is properly cited and the use is non-commercial. See: http:// creativecommons.org/licenses/by-nc/4.0/

\section{REFERENCES}

1. Windecker S, Kolh P, Alfonso F, et al. 2014 ESC/EACTS Guidelines on myocardial revascularization. The Task Force on Myocardial Revascularization of the European Society of Cardiology (ESC) and the European Association for Cardio-Thoracic Surgery (EACTS) developed with the special contribution of the European Association of Percutaneous Cardiovascular Interventions (EAPCI). Eur Heart J 2014;35:2541-2619. 
2. O'Gara PT, Kushner FG, Ascheim DD, et al. 2013 ACCF/AHA guideline for the management of ST-elevation myocardial infarction: executive summary: a report of the American College of Cardiology Foundation/American Heart Association Task Force on practice guidelines. Circulation 2013;127:529-55.

3. McManus D, Gore J, Yarzebski J, et al. Recent trends in the incidence, treatment, and outcomes of patients with ST and non-ST-segment acute myocardial infarction. Am J Med 2011;124:40-7.

4. Eagle KA, Nallamothu BK, Mehta RH, et al. Trends in acute reperfusion therapy for ST-segment elevation myocardial infarction from 1999 to 2006: we are getting better but we have got a long way to go. Eur Heart J 2008;29:609-17.

5. Ward MJ, Kripalani S, Zhu Y, et al. Incidence of emergency department visits for ST-elevation myocardial infarction in a recent six-year period in the United States. Am J Cardiol 2015;115:167-70.

6. Corr U, Carré F, Heuschmann P, et al. Secondary prevention through cardiac rehabilitation: physical activity counselling and exercise training. Eur Heart J 2010;31:1967-76.

7. Beauchamp A, Worcester M, Ng A, et al. Attendance at cardiac rehabilitation is associated with lower all-cause mortality after 14 years of follow-up. Heart 2013;99:620-5.

8. Levey AS, Stevens LA, Schmid $\mathrm{CH}$, et al. A new equation to estimate glomerular filtration rate. Ann Intern Med 2009;150:604-12.

9. Thygesen K, Alpert JS, Jaffe AS, et al. Third universal definition of myocardial infarction. Circulation 2012;126:2020-35.

10. Jernberg $\mathrm{T}$, Johanson $\mathrm{P}$, Held $\mathrm{C}$, et al. Association between adoption of evidence-based treatment and survival for patients with ST-elevation myocardial infarction. JAMA 2011;305:1677-84.

11. Shahzad A, Kemp I, Mars C, et al. Unfractionated heparin versus bivalirudin in primary percutaneous coronary intervention (HEAT-PPCI): an open-label, single centre, randomised controlled trial. Lancet 2014;6736:1-10.

12. Stone GW, Witzenbichler B, Guagliumi G, et al. Bivalirudin during primary $\mathrm{PCl}$ in acute myocardial infarction. $N$ Engl $\mathrm{J} \mathrm{Med}$ 2014;358:2218-30.

13. Montalescot G, Dallongeville J, Van Belle E, et al. STEMI and NSTEMI: are they so different? 1 Year outcomes in acute myocardial infarction as defined by the ESC/ACC definition (the OPERA registry). Eur Heart J 2007;28:1409-17.

14. Ghadri JR, Jaguszewski M, Sacron A et al. Current outcome of acute coronary syndromes: data from the Zurich-acute coronary syndrome (Z-ACS) registry. Kardiovaskulare Medizin 2013;16:115-22.

15. Pedersen $\mathrm{F}$, Butrymovich $\mathrm{V}, \mathrm{Kelbæk} \mathrm{H}$, et al. Short- and long-term cause of death in patients treated with primary PCI for STEMI. J Am Coll Cardiol 2014;64:2101-8.

16. Wald DS, Morris JK, Wald NJ, et al. Randomized trial of preventive angioplasty in myocardial infarction. $N$ Engl $J$ Med 2013;369:1115-23.
17. Thiele H, Zeymer U, Neumann FJ, et al. Intra-aortic balloon counterpulsation in acute myocardial infarction complicated by cardiogenic shock (IABP-SHOCK II): final 12 month results of a randomised, open-label trial. Lancet 2013;382:1638-45.

18. Inohara $\mathrm{T}$, Miyata $\mathrm{H}$, Ueda I, et al. Use of intra-aortic balloon pump in a Japanese multicenter percutaneous coronary intervention registry. JAMA Intern Med 2015;175:1980-2.

19. Rollando D, Puggioni E, Robotti S, et al. Symptom onset-to-balloon time and mortality in the first seven years after STEMI treated with primary percutaneous coronary intervention. Heart 2012;98:1738-42.

20. Menees DS, Peterson ED, Wang Y, et al. Door-to-balloon time and mortality among patients undergoing primary $\mathrm{PCl}$. $N$ Engl $\mathrm{J}$ Med 2013;369:901-9.

21. Farshid A, Allada C, Chandrasekhar J, et al. Shorter ischaemic time and improved survival with pre-hospital STEMI diagnosis and direct transfer for primary PCl. Heart Lung Circ 2014;24:234-40.

22. Smith SC, Benjamin EJ, Bonow RO, et al. AHA/ACCF secondary prevention and risk reduction therapy for patients with coronary and other atherosclerotic vascular disease: 2011 update-a guideline from the American Heart Association and American College of Cardiology Foundation Endorsed by the World. J Am Coll Cardiol 2011;58:2432-46

23. Marso SP, Mercado N, Maehara A, et al. Plaque composition and clinical outcomes in acute coronary syndrome patients with metabolic syndrome or diabetes. JACC Cardiovasc Imaging 2012;5: S42-52.

24. Baber U, Stone GW, Weisz G, et al. Coronary plaque composition, morphology, and outcomes in patients with and without chronic kidney disease presenting with acute coronary syndromes. JACC Cardiovasc Imaging 2012;5:S53-61.

25. Kusumoto FM, Calkins H, Boehmer J, et al. HRS/ACC/AHA expert consensus statement on the use of implantable cardioverter-defibrillator therapy in patients who are not included or not well represented in clinical trials. Circulation 2014;130:94-125.

26. Moss AJ, Zareba W, Hall WJ, et al., Multicenter Automatic Defibrillator Implantation Trial II Investigators. Prophylactic implantation of a defibrillator in patients with myocardial infarction and reduced ejection fraction. N Engl J Med 2002;346:877-83.

27. Shiga T, Hagiwara N, Ogawa $\mathrm{H}$, et al. Sudden cardiac death and left ventricular ejection fraction during long-term follow-up after acute myocardial infarction in the primary percutaneous coronary intervention era: results from the HIJAMI-II registry. Heart 2009;95:216-20.

28. Solomon SD, Zelenkofske S, McMurray JJ, et al., Valsartan in Acute Myocardial Infarction Trial (VALIANT) Investigators. Sudden death in patients with myocardial infarction and left ventricular dysfunction, heart failure, or both. N Engl J Med 2005;352:2581-8. 